\title{
Evaluation of the Maternal Death Surveillance and Response System, Sanyati, Zimbabwe 2017
}

\author{
Article by S. Tapesana ${ }^{1}$, D. Chirundu ${ }^{2}$, T. Juru ${ }^{3}$, G. Shambira ${ }^{4}$, N. Gombe ${ }^{5}$, M. \\ Tshimanga ${ }^{6}$ \\ 1,3,4,5,6 Department of Community Medicine, University of Zimbabwe, Zimbabwe \\ ${ }^{2}$ Kadoma City Health Department, Kadoma \\ E-mail: 1drstanelytaps@gmail.com, ${ }^{2}$ dchirundu@me.com, ${ }^{3}$ tjuru@zimfetp.net, \\ ${ }^{4}$ gshambira@yahoo.com, ${ }^{5}$ ntgombent@zimfetp.net, ${ }^{6}$ mtshimanga@yahoo.com
}

\begin{abstract}
Background: Combating maternal mortality requires a functional Maternal Death Surveillance and Response system (MDSR). In Zimbabwe, maternal mortality ratio was 651 deaths per 100000 live births in 2015. Only five out of 25 deaths were notified on time in Sanyati District 2015-2016. We evaluated the system to determine if it was serving its intended purpose.

Methods: We conducted a descriptive cross sectional study using the MDSR technical guidance and the updated CDC guidelines for evaluating public health surveillance systems. Data were collected using interviewer administered questionnaires, key informant interviews, focused group discussions and records review. Medians, proportions and frequencies were calculated using Epi Info 7. Qualitative data was analysed using word cloud.

Results: We interviewed 216 health workers out of 230 involved in MDSR. Ninety-nine percent were nurses. Sixty-two percent correctly defined a maternal death. Ninety-eight percent found the system useful. Those confident to notify a maternal death were 139(68\%). Easy access to case information was reported by 91(62\%). Data was analysed by 138(80\%) and used to monitor maternal mortality trends. Information sharing with stakeholders was reported by 59(31\%). Ninety-seven percent were willing to continue participating. The cost of notifying a single death was USD\$246.09. All community deaths were not being captured by the system as reported by 128(59\%). Key informants and focused group discussions outcomes highlighted concerns of unreported community deaths. There was no zero reporting of community maternal deaths.

Conclusion: The MDSR system was useful, acceptable, simple and not costly. The system was also unstable, unrepresentative and not timely. Minimal stakeholder and community involvement, inadequate human resources and training, hampered the systems performance. We recommend health worker training and conducting an interventional study to assess the effectiveness of community involvement in reporting maternal deaths.
\end{abstract}

Keywords: Maternal Death, Surveillance, Response, Sanyati, Zimbabwe.

\section{Background}

Maternal mortality remains a global public health concern and part of the agenda for sustainable development. An increasing concern of dying mothers lead to the promulgation of the Millennium Developmental Goals (MDG) in year 2000 (WHO). The fifth MDG target was to reduce maternal mortality by $75 \%$ by year $2015{ }^{1}$ The global maternal mortality decreased to 210 deaths per 100000 live births between 1990 and 2013 with Sub-Saharan Africa lagging behind with a maternal mortality of 510 deaths per 100000 live births and contributing $42 \%$ of the global deaths. ${ }^{2}$ Following uncertainties in meeting the $5^{\text {th }}$ MDG target in 2010, the Commission on Information and Accountability of the Global Strategy for Women's and Children's Health recommended the implementation of an accountability framework. This framework adopted by countries was based on national oversight, accurate and comprehensive monitoring of results, regular multi-stakeholder review of data and 
responses, all being key features of traditional surveillance and response systems. Thus, a Maternal Death Surveillance and Response (MDSR) Technical Working Group (TWG) was established and chaired by the World Health Organization. ${ }^{3}$ The Maternal Death Surveillance and Response system was formed in 2013 as a brainchild of the MDSR technical working group.

The MDSR system involves a continuous action cycle of ongoing systematic collection, analysis, interpretation and timely dissemination of maternal mortality data to those in need so that appropriate action is made. This system introduced the missing link 'response' component that did not exist in previous maternal death surveillance systems. The response part of the MDSR system entails appropriate action and strategies to prevent future deaths of similar nature from occurring. ${ }^{4}$ The system provides information that effectively guides actions to eliminate preventable maternal mortality at health facilities and in the community, counting every maternal death, permitting an assessment of the true magnitude of maternal mortality and the impact of actions (the response) taken to reduce it.

\section{MDSR system in zimbabwe}

In Zimbabwe, the MDSR system was adopted in 2013 alongside the new socio-economic policy framework, Zimbabwe Agenda for Sustainable Socio-Economic Transformation (Zim Asset). This followed the countries unified efforts towards maternal mortality reduction. The adopted system entails identifying maternal deaths, reporting and response from community to national level. The cascade of events in this system is triggered by a maternal death at any level as shown in Figure 1.

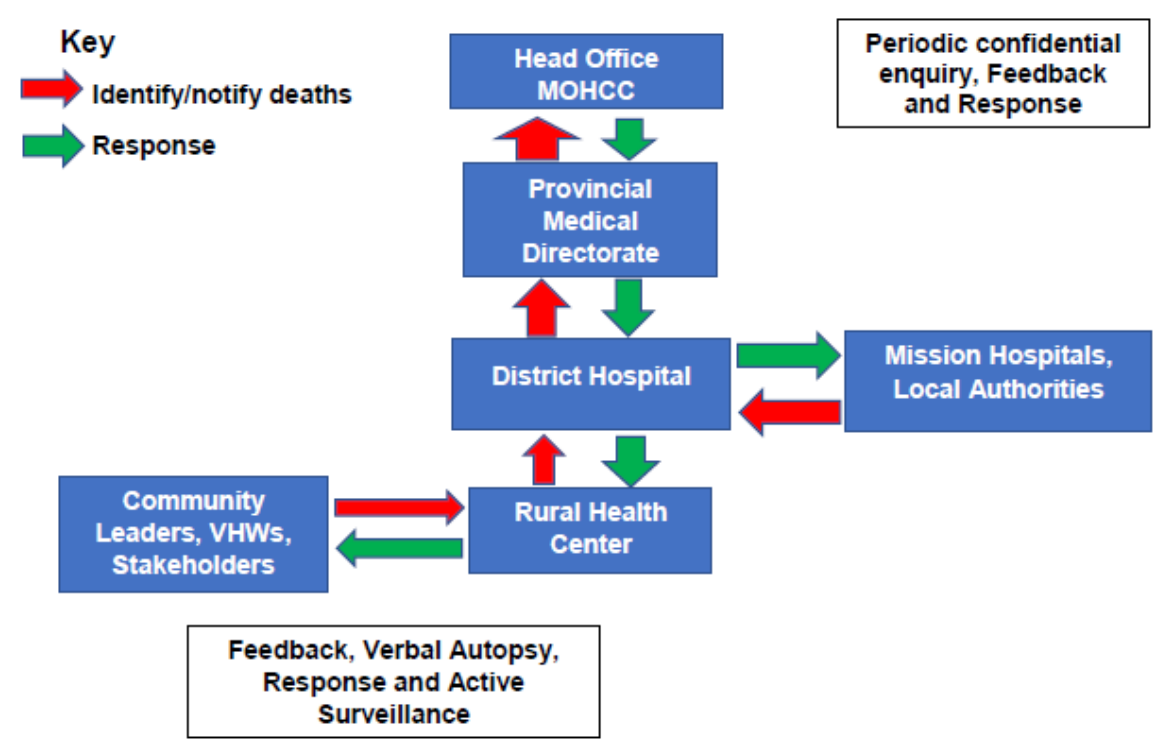

Figure 1. Links in a Maternal Death Surveillance and Response (MDSR) System, Zimbabwe

Following a community maternal death, a team from the immediate health facility carries out an investigation. A confirmed maternal death is notified to the next level by phone within 48 hours. Notification of deaths to the provincial medical directorate is done within fourteen days by completing the maternal death notification form in triplicate and forwarding two copies. Of the two copies sent to the Provincial Medical Directorate, one is forwarded to the Ministry of Health and Child Care (MOHCC) Head Office. The maternal death review committee reviews all the maternal deaths at district level. Confidentiality is maintained through the reviews, no names are used and no blame. At each level, there is feedback and dissemination of information. Case specific recommendations are made during maternal death audits. Periodic monitoring and evaluation of the response is done at each level of care. 
An analysis of the MDSR system in Sanayti District (2015-2016), showed that: five deaths out of twenty-five had been timely notified (within two weeks) and the surveillance system had missed four maternal deaths. Furthermore, not all recommendations were implemented following the maternal death audits. Reasons for non-compliance to the MDSR system remained obscure. We evaluated the system to determine if it was serving its intended purpose.

\section{Methodology}

\section{Study design}

We conducted a descriptive cross sectional study using the CDC updated guidelines for evaluating public health surveillance systems and the MDSR technical guidelines. ${ }^{4}$

\section{Study site}

The study was done in Sanyati District, which is one of the seven districts in Mashonaland West Province, Zimbabwe. The districts population is 215 842. The district has two referral centres, Kadoma General Hospital located in Kadoma in the southern end of the district and Sanyati Mission Hospital located 110 kilometres from Kadoma in a Western direction. Amongst the twenty-six health facilities are, 16 rural health centres, five local authority clinics and two mine clinics. Kadoma General Hospital offers a full package of comprehensive emergency obstetric and newborn care. The population to clinic ratio ranged from 2481 to 27439 people per clinic. Women of childbearing age were 56119 as of January 2017. Pregnant women were 10792 (5\%) with8 634 expected deliveries per year.

\section{Study subjects and sample size}

The study population was all health workers involved in maternal death surveillance and response and the community representativesin Sanyati District. The total population involved in MDSR was 230 health workers. We conveniently enrolled 216 health workers into the study. All the 25 maternal death notification forms completed between 2015-2016 in Sanyati District were also reviewed.

\section{Study variables}

Among the variables we studied were: usefulness of the system, health worker knowledge, cost of running the system and system attributes (simplicity, data quality, acceptability, representativeness, timeliness, and stability).

\section{Data collection and analysis}

Data were collected using pretested interviewer administered questionaires, key informant interviews, focused group discussion and records review. Quantitative data was analysed using Epi Info 7.2.0.1 ${ }^{\mathrm{TM}}(\mathrm{CDC}, 2012)$ and frequencies, medians and proportions were generated. Qualitative data was analysed using Word Cloud software and a word cloud was generated.

\section{Ethical considerations}

We obtained written informed consent from all participants. Permission to proceed was obtained from the Ministry of Health and Child Care and the Health Studies Office.

\section{Results}

\section{Demography}

Two hundred and sixteen respondents were interviewed as primary participants. The majority were nurses214 (99\%). The median years working in Sanyati District was $8\left(\mathrm{Q}_{1}=3\right.$; $\left.\mathrm{Q}_{3}=11\right)$ years whilst the median years in service was $8\left(\mathrm{Q}_{1}=7 ; \mathrm{Q}_{3}=17.5\right)$ years for the health workers. The demographic characteristics of respondents are shown in table 1 . 
Texila International Journal of Public Health

Volume 5, Issue 2, Jun 2017

\section{Health worker knowledge}

The health worker knowledge on maternal death notification and basic definitions was assessed using a battery of five questions. Twenty-seven percent $(n=54)$ and 127(62\%) respondents correctly defined a woman of reproductive age and maternal death respectively. The majority of the staff $185(89 \%)$ knew the timeline for notifying a maternal death. Presented in table 2 is an assessment of the health worker knowledge.

\section{System attributes}

\section{Usefullness}

The usefullness of the MDSR system was assessed focusing on whether the health workers were using case notification data and what they were using it for.Eighty percent $(n=138)$ of respondents reported analyzing and using the information for monitoring maternal mortality trends. Ninety-two respondents $(53 \%)$ reported action being taken following analysis of the information at district level. The training of 41 nurses in emergency obstetric and neonatal care, deployment of nurse midwives in female wards and deployment of nurse midwives to the three furthest rural health facilities was part of the action implemented following analysis of the collected information. Thirty-one percent health workers indicated sharing information with stakeholders in the form of health education, meetings and written reports. All the minutes and reports for the 25 maternal deaths were available. Health workers and clients seeking care at the facilities were the stakeholders involved in information dissemination. There was no involvement of local stakeholders such as village health workers, community representatives and business people in the community. Ninety-two (47\%) reported receiving feedback from the District Health Executive among these, 179(83\%) reported using the feedback reports. All the health workers $(100 \%)$ reported that the system should remain in place while 204(98\%) percieve the system to be useful. An assessment of the systems usefulness is shown in table 3 .

\section{Simplicity}

A panel of five questions was used to assess simplicity of the system. Forty-eight (24\%) reported having ever completed a maternal death notification form whilst eight (17\%) of the respondents reported facing difficulties during the notification process. Difficulties were encountered in classifying the death as either avoidable or not avoidable. The reported average time to complete the maternal death notification form was 60 minutes. The need for specialised training was cited by $162(79 \%)$ while $139(68 \%)$ reported to be confident to complete a maternal death notification form. Sixty-two percent $(n=91)$ reported easy access to case information. An assessment of the simplicity isshown in table 3.

\section{Data quality, acceptability, timeliness and representativeness}

Of the 25 maternal death notification forms analysed, completeness was $100 \%$. All fields were clear and easy to read. All 216 respondents interviewed completed all questions successfully without question refusal. Ninety-four percent were willing to notify a maternal death while $210(97 \%)$ were willing to participate in maternal death review meetings. Nonetheless $163(78 \%)$ felt that there was confidentiality during conduction of maternal death audits. Hundred and twenty-two (59\%) reported that there was no blaming of individuals during maternal death audits while $62(30 \%)$ reported blaming of individuals and $23(11 \%)$ felt there was some blame at times. Five of the 25 deaths were notified and reviewed on time (within seven days) of the maternal death. Fifty-nine percent $(n=123)$ health workers reported that, not all community deaths were being picked by the surveillance system. Sixty-two percent of the health workers reported having enough time to complete the maternal death notification forms. 


\section{Stability}

Forty-eight $(23 \%)$ of the health workers were trained in maternal death notification. Seventy-two (34\%) workers were trained in emergency obstetric and neonatal care, which is an intergral part in response to maternal mortality reduction.The completed maternal death notification forms were secured in lockers at all the centers. Maternal death notification forms were readily available and no stock outs were recorded.

\section{Maternal death audits analysis and recommendations}

Twenty-five maternal deaths were analysed using word cloud. The qualitative analysis of maternal death audits, recommendations and response is shown in Figure 2.

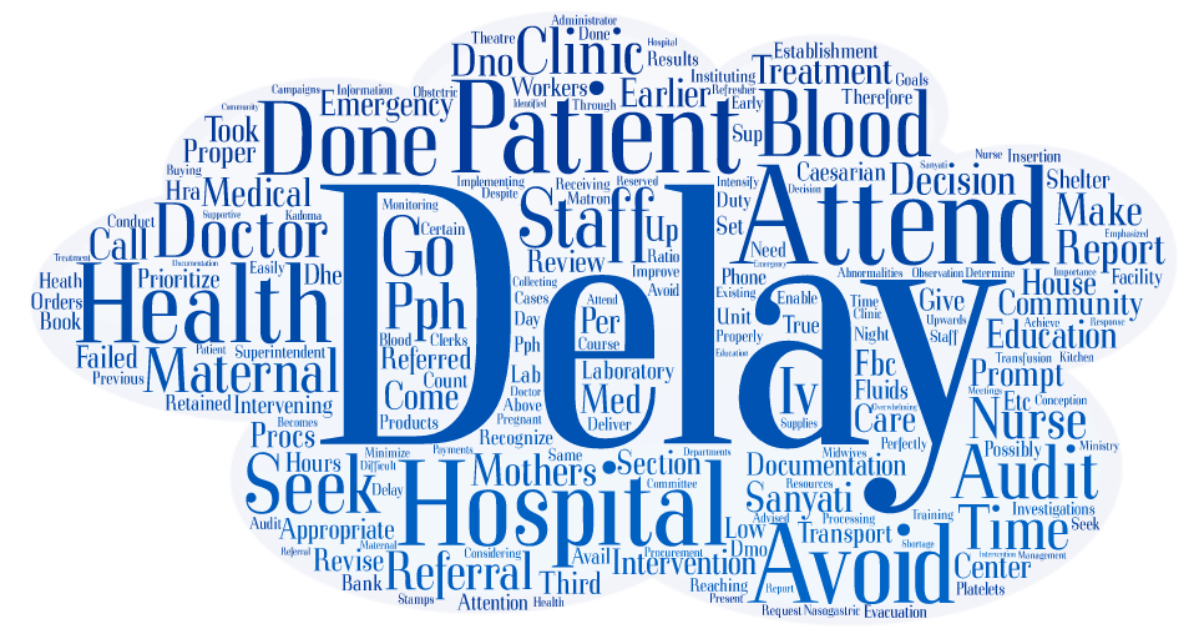

Figure 2. Word cloud output for qualitative analysis of maternal death audits, recommendations and response, sanyati, 2017.

First and second delays prolonged the time needed to institute interventions for the patients. Staff shortages at the referral hospital particularly doctor and nurse shortages were linked to maternal deaths. Postpartum haemorrhage was a common cause of maternal deaths. Delayed cross matching and transfusion of blood to patients by on call laboratory personnel was noted to be linked to maternal deaths. Most of the deaths $(21 / 25)$ were classified as avoidable. Among the recommendations of the audits was prioritization of blood and iv fluids for maternity cases. Team work in managing patients by on call health workers was recommended as part of an effective response strategy.

\section{Focused group discussion outcomes}

A focused group discussion was conducted in rural Sanyati. The group was made up of four headmen, three village health workers, three councillors and three chief's representatives. The following concerns were highlighted during the focused group discussion.

a) The chief's council confirmed that community maternal deaths were occurring because of miscarriages and other complications of pregnancies.

b) Home deliveries were occurring in the communities as reported by village health workers and herdmen.

c) The cost of booking and delivery which was reported to be USD $\$ 7$ and USD $\$ 32$ respectively were among the barriers to seeking medical care among pregnant women.

d) Staff attitudes were also a barrier to seeking care at Sanyati Mission Hospital such that the community prefered to seek help from traditional healers and apostolic churches.

e) Doctors were not readily available and there was a high turnover of the same at Sanyati Mission Hospital.

f) Clients were made to pay consultation fees and referred elsewhere to buy medication. 
Texila International Journal of Public Health

Volume 5, Issue 2, Jun 2017

g) There was lack of support for the village health workers by the existing health system.

h) There was no involvement of the local leadership and community in health issues of the district.

Some of the pertinent issues recorded during the focused group discussion are quoted as follows:

\section{Speaker A}

'Nurses at the hospital should be different from soldiers and police force Patients must be free when approaching the hospital'

\section{Speaker B}

'People are afraid and hesitating to seek medical attention at the hospital owing to the bad health worker staff attitudes'

\section{Speaker C}

In local language (Shona): 'Vanamukotivanodaidzwa kana murwereauyaasihavauyikuzomubatsira, vamwevachovanouyakuzorapavarwerevakadhakwa' English translation

'The nurses do not attend to the sick patients when called for help; some of them attend to patients whilst they are drunk'

\section{Speaker D}

in local language (Shona): Hospital irikuremeravanhu, irikuvandanechigumwe, vakadzivakazvitakura nevagarivemunovarikunonokakubatsirwapachipatara.

\section{English translation}

The hospital has become a burden for the community, they delay offering medical care for the community and pregnant mothers.

\section{Direct resources used to operate the system}

The Government of Zimbabwe and partners through the MOHCC provide the resources for operating the MDSR system. At Sanyati Mission Hospital, there was one doctor instead of three as per establishment, no blood bank, no theatre nurse and no functioning ambulance. The doctor, midwife and nurse to population ratio was two, 42 and 74 per 10000 population respectively.

\section{Cost of auditing and notifying a maternal death}

Assuming a nurse's basic salary of USD $\$ 300$ per month and $180 \mathrm{~km}$ being the distance of the furthest clinic from the district offices, the total cost of running the system per institutional maternal death notified was USD $\$ 246.09$. This was calculated from the time taken for data collection, notification and report writing which was assumed to be 60 minutes per case, call charges of USD $\$ 0.09$ per minute assuming a maximum of 15 minutes required to convey all case information. Fuel costs for sending maternal death notification form and a health worker to attend maternal death review meeting at the district hospital on separate days was taken into consideration.

\section{Discussion}

This descriptive cross-sectional study sought to determine the performance of the MDSR system in Sanayti District 2017.The use of information from this system in monitoring maternal mortality trends indicates acceptability of the system to the users. Had the users not accepted the system this would be reflected by none use of the information generated by this system. Use of information generated by the system is a proxy to the usefulness of the system. However, action was taken in about half of the scenarios. This finding could be explained by 
the lack of resources to implement response strategies as was highlighted by the key informants. The lack of a laboratory at Sanyati Mission could have affect the implementation of recommendations following maternal death audits.

The proportion reporting sharing information with stakeholders was low (31\%). This could be attributed to nonexistence of a health center committee in Sanyati rural. Focused group discussion findings also highlighted non-involvement of the community representatives and stakeholders. Information concerning the systems performance was shared among health personnel and not shared with the stakeholders. Village health workers also shared their concerns of non-support by the health professionals at the health facilities. The community and respondents were concerned about the lack of feedback on the systems performance from the district health executive. The lack of feedback could be due to competing priorities for the health workers and non-existence of communication channels between the health system and the community. Non involvement of the community and stakeholders in the system and bad health worker attitudes have seen the community resorting to unsafe practices as indicated by the chief's council.

Most of the respondents could not define a woman of reproductive age which is a woman of age 15 to 49 years. Failure to define this term implies a weakness in the surveillance system, as the workers are not aware of the target group for surveillance of maternal deaths. Not knowing the definition of a maternal death may result in misclassification of deaths and misdirected use of resources. Although forty-eight (24\%) respondents reported having ever completed a maternal death notification form, this does not reflect the simplicity of the system. This low proportion is explained by the fact that maternal deaths are rare events hence we expect to have a lower proportion that should have ever completed a form. The difficult area of concern in the notification process was classification of the maternal death as either avoidable or not avoidable.

All the 25 maternal death notification forms were complete and legible. The completeness of the death notification forms is a proxy to the acceptability and simplicity of the system. Had this system been unacceptable and complicated, there could have been incompleteness of the maternal death notification forms. There was no question refusal and no dropouts for all the respondents interviewed, hence implying that the system was acceptable to the users. Acceptability of the system is shown by the majority of respondents who reported willingness to notify deaths (94\%) and $97 \%$ willingness to continue attending maternal death audits. Nonetheless $163(78 \%)$ reported that confidentiality was maintained during maternal death audits. Health worker confidentiality was difficult to maintain owing to the few health workers at a station such that it would be difficult to maintain confidentiality. Blaming of individuals during conduction of maternal death audits was a concern and reported by $41 \%$ of the respondents.

Fifty-nine percent of the health workers reported that; not all community maternal deaths were reported. Among the reasons highlighted were the existence of some religious groups that did not allow their followers to seek health care. The surveillance system was not readily available to capture maternal deaths at community level. The stability of the response component was threatened by lack of resources and expertise. The World Health Organisation (WHO) recommends 10 doctors, 20 midwives and 20 nurses per 100000 populations. ${ }^{5}$ Using the WHO guide, the number of doctors in the district were not adequate. Although the ratios for nurses is above the recommended, there is still inadequate and inefficient distribution of the available human resources to the peripheral health centres. Taking into account the district's population of 215842 and the available health facilities, there is still an unmet need for healthcare facilities. The lack of facilities that provide a full comprehensive emergency obstetric and new born care package results inwomen succumbing to birth related complications. The high population to clinic ratio leads to attrition of health workers and resources thereby compromising the quality of care delivered. The accessibility of roads linking health centres has resulted in delays in transferring patients there by leading to poor outcomes. 
Texila International Journal of Public Health

Volume 5, Issue 2, Jun 2017

The total cost of USD $\$ 246$ for notifying a single maternal death is justifiable considering the severity of the health event under surveillance. However, this cost will be reduced markedly following full implementation of the electronic notification of maternal deaths that is being piloted.

\section{Limitation of the study}

Inadequate time and resources limited our ability to comprehensively evaluate the response component of the MDSR system.

\section{Conclusions}

Following triangulation from several sources, we conclude that the system was useful, not costly, acceptable and simple. However, it was unstable, untimely and not representative. These findings may be attributed to non-involvement of the community and stakeholders, lack of resources and lack of training.

\section{Recommendations}

We recommend conducting a before and after study to determine effectiveness of community involvement in reporting maternal deaths. We also endorse the introduction of the MDSR system component in nurse midwifery training sin order to strengthen case detection and notification. We also recommend increasing posts for health workers involved in the MDSR system and establishing a blood bank at Sanyati Mission Hospital.

Table 1. Demographic characteristics of respondents, sanyati, 2017

\begin{tabular}{lll}
\hline Variable & Category & Frequency \\
\hline Sex & Female & $155(74)$ \\
& Male & $56(26)$ \\
Midwife & & $84(41)$ \\
Registered General Nurse & & $75(33)$ \\
Primary Care Nurse & & $50(25)$ \\
Government Medical Officer & & $2(1)$ \\
Median years in Sanyati & $8\left(\mathrm{Q}_{1}=3 ; \mathrm{Q}_{3}=11\right)$ & \\
District & & \\
Median years in service & $8\left(\mathrm{Q}_{1}=7 ; \mathrm{Q}_{3}=17.5\right)$ \\
\hline
\end{tabular}

Table 2. Health worker knowledge on maternal death notification, sanyati, 2017

\begin{tabular}{|c|c|c|c|}
\hline \multirow[t]{2}{*}{ Variable } & \multicolumn{3}{|c|}{ Frequency of Response n (\%) } \\
\hline & Correct & Incorrect & Don't know \\
\hline $\begin{array}{l}\text { Defining a woman of } \\
\text { reproductive age }\end{array}$ & $54(27)$ & $132(66)$ & $14(7)$ \\
\hline Defining a maternal death & $127(62)$ & $72(35)$ & $7(3)$ \\
\hline $\begin{array}{l}\text { Time limit for notification of } \\
\text { maternal death by phone }\end{array}$ & $185(89)$ & $5(2)$ & $18(9)$ \\
\hline $\begin{array}{l}\text { Time limit of notifying the } \\
\text { provincial directorate of a } \\
\text { maternal death }\end{array}$ & $120(59)$ & $4(2)$ & $81(39)$ \\
\hline $\begin{array}{l}\text { Number of maternal death } \\
\text { notification forms completed }\end{array}$ & $49(24)$ & $79(39)$ & $74(37)$ \\
\hline
\end{tabular}


Table 3. Usefulness and simplicity of the mdsr system, sanyati, 2017

\begin{tabular}{ll}
\hline Variable & Frequency n (\%) \\
\hline Usefulness & $138(80)$ \\
Analyse information & $201(97)$ \\
Monitoring maternal mortality trends & $92(53)$ \\
Action after analysis & $59(31)$ \\
Information shared with stakeholders & $92(47)$ \\
Received feedback from District Health Executive & $85(39)$ \\
Use feedback information & $204(98)$ \\
Find system useful & \\
Simplicity & $48(24)$ \\
Ever completed a maternal death notification form & $8(17)$ \\
Difficulties in completing a maternal death notification & \\
form & $139(68)$ \\
Confident to complete a maternal death notification form & $162(79)$ \\
Needs training to complete a maternal death notification & \\
form & $91(62)$ \\
Ease of access to case information & \\
\hline
\end{tabular}

\section{Acknowledgements}

We would like to acknowledge the following organisations and individuals for making our study a success: Kadoma City, Kadoma General Hospital, Simbarashe Tashaya, Obert Chingozho and Blessing Banda.

\section{References}

[1]. Agaro C, Kashesya, J. B, Waiswa P, Sekandi J. N, Tusiime S, Anguzu R: The conduct of maternal and perinatal death reviews in Oyam District, Uganda: a descriptive cross-sectional study BMC Women's Health (2016) 16:38.

[2]. Barnett S, Nair N, Tripathy P, et al: A prospective key informant surveillance system to measure maternal mortality - findings from indigenous populations in Jharkhand and Orissa, India. BMC Pregnancy and Childbirth 2008, 8:6.

[3]. Centres for Disease Control and Prevention, Updated Guidelines for Evaluating Public Health Surveillance Systems, Recommendations from the Guidelines Working Group, MMWR Recommendations and Reports, July 27, 2001;50(RR-13):1-35,

http://www.cdc.gov/mmwr/preview/mmwrhtml/rr5013a1.htm, Accessed 28 September 1300 Hours, 2016.

[4]. Cantwell R, Clutton-Brock T, Cooper G, Dawson A, Drife J, Garrod D, et al. Saving Mothers' Lives: Reviewing maternal deaths to make motherhood safer:2006-2008. The eighth report on confidential enquiries into maternal deaths in the United Kingdom. BJOG 2011; 118(Suppl. 1):1-203.

[5]. Danel I, Graham WJ, Boerma T: Maternal death surveillance and response. Bull World Health Organ 2011, 89(11):779. 779A.

[6]. Gilmore K, Gebreyesus TA: What will it take to eliminate preventable maternal deaths? Lancet 2012, 380(9837):87-88.

[7]. Hounton S, Bernis L, Hussein J, Graham W. J, Danel I, Byass P: Towards elimination of maternal deaths: maternal deaths surveillance and response. Reproductive Health 2013 10:1.

[8]. IDSR - Technical Guidelines for Integrated Disease Surveillance and Response in the African Region, 2nd Edition - 2010

[9]. Ina May Gaskin: Maternal Death in the United States A Problem Solved or a Problem Ignored? The Journal of Perinatal Education Spring 2008, Volume 17, Number 2.

[10]. Negandhi PH, Neogi SB, Chopra S, Phogat A, Sahota R, Gupta R:Improving reporting of infant deaths, maternal deaths and stillbirths in Haryana, India. Bulletin of the World Health Organization

[11]. Prata N, Passano P, Sreenivas A and Gerdts C.E: Maternal mortality in developing countries: Challenges in scaling up priority interventions, Women's Health (2010). 
Texila International Journal of Public Health

Volume 5, Issue 2, Jun 2017

[12]. Sombie I, Meda N, Hounton S, Bambara M, Ouedraogo TW, Graham W: Missing maternal deaths: lessons from SouroSanou University Hospital in Bobo-Dioulasso, Burkina Faso. Trop Doct 2007, 37(2):96-98.

[13]. The Zimbabwe Demographic and Health Survey 2015 key indicators

[14]. United Nations Zimbabwe 2012 Millennium development goals progress report.

[15]. World Health Organisation, UNICEF, UNFPA, The World Bank, United Nations Populations Division. Trends in Maternal Mortality: 1990 to 2013. Geneva: WHO:2014

http://www.who.int/reproductivehealth/publications/monitoring/maternalmortality-2013/en/Accessed 28 September 2016.

[16]. World Health Organization. Maternal Death Surveillance and Response: Technical guidance. Information for action to prevent maternal death. Geneva: WHO; 2013. http://www.who.int/maternal_child_adolescent/documents/maternal_death_surveillance/en/ Accessed 28 September 2016.

[17]. World Health Organisation (2012). The WHO application of ICD-10 to deaths during pregnancy, childbirth and the puerperium: ICD-MM. Geneva: WHO. Available at: http://www.who.int/reproductivehealth/publications/monitoring/9789241548458/en/

[18]. WHO (2011). Commission on information and accountability for women's and children's health. keeping promises, measuring results. http://www.who.int/topics/millennium_development_goals/ accountability_commission/Commission_Report_advance_copy.pdf. Accessed 11 September 2016.

[19]. World Bank (2011). Maternal Death Audit as a Tool Reducing Maternal Mortality. Washington, DC: World Bank.

http://siteresources.worldbank.org/INTPRH/Resources/376374-1278599377733/ Maternal Death Audit Accessed 28 September 2016 